\title{
Synchronous multiple primary malignant melanoma in a patient with atypical mole syndrome
}

\author{
LO Ajekigbe MBBS FRCSG, PE Baguley MBBS FRCPC FRCSplasC \\ Middlesbrough General Hospital, Middlesbrough, United Kingdom
}

\section{LO Ajekigbe, PE Baguley. Synchronous multiple primary malignant melanoma in a patient with atypical mole syndrome. Can J Plast Surg 2000;8(6):229-231.}

Multiple primary malignant melanoma developing in people with atypical mole syndrome is well documented but rare. Synchronous occurrence of such melanomas is even rarer. The present case report, while not unique, provides an excellent opportunity to remind clinicians of presentation and management of atypical mole syndrome, while emphasizing the higher risk of developing malignant melanoma.

Key Words: Atypical mole syndrome; Synchronous multiple primary malignant melanoma

Apparition d'un mélanome malin primitif multiple synchrone chez un patient atteint du syndrome atypique de naevi

RÉSUMÉ : L'apparition d'un mélanome malin primitif multiple chez les personnes atteintes du syndrome atypique de naevi est bien documentée mais rare. Toutefois, l'apparition synchrone de plusieurs mélanomes est encore plus rare. Voici un exposé de cas, non unique d'ailleurs, qui rappelle aux cliniciens non seulement la présentation et le traitement du syndrome atypique de naevi, mais aussi les risques accrus de mélanome malin qui lui sont associés.

\section{CASE PRESENTATION}

The case of a 48-year-old man is presented. He has lived in the United Kingdom all his life except for annual family holidays abroad. The patient has Fitzpatrick type II skin and had no previous personal or family history of melanoma. However, he described himself and his two daughters as having "a large number of moles."

The patient presented to his family doctor in January 1999 with a history of a changing mole on his right hypochondrium. It was getting bigger and darker. This mole, like several others, mainly on his trunk, had been present for several years. He was referred to and seen urgently in the dermatology department where an urgent excision biopsy was carried out. The histology confirmed a superficial spreading malignant melanoma with Breslow thickness of $2.2 \mathrm{~mm}$. He was then referred to the plastic surgery department for further care.

He was seen at the plastic surgery clinic within one week of the histological diagnosis and within three weeks of his presentation to his family doctor. At his first visit, he was found to have more than 100 naevi of varying sizes that were mainly on his trunk. Five of these naevi were dysplastic or early melanoma (Figures 1-5). He had no palpable peripheral lymph nodes.

A directed lymph node biopsy, using preoperative technetium $^{99}$ colloid lymphoscintigraphy, intraoperative dye injection and hand-held gamma probe, was carried out as part of the management of his right hypochondrial melanoma. The dynamic image of the lymphoscintigram (Figure 6) showed simultaneous drainage to both axillae only. Figure 7 showed the sentinel nodes. The five suspicious lesions (Figures 1-5) were biopsied at the same time. The sentinel node from the right axilla was positive, and a formal block dissection was carried out; the node from the left axilla was negative. Further primary malignant melanoma was confirmed on the right shoulder (Breslow thickness on the right shoulder of

Correspondence: Mr L Ajekigbe, Middlesbrough General Hospital, Middlesbrough TS5 5AZ, United Kingdom. Telephone 01642854216 ,

fax01642854175,e-mail laje@fsmail.net 


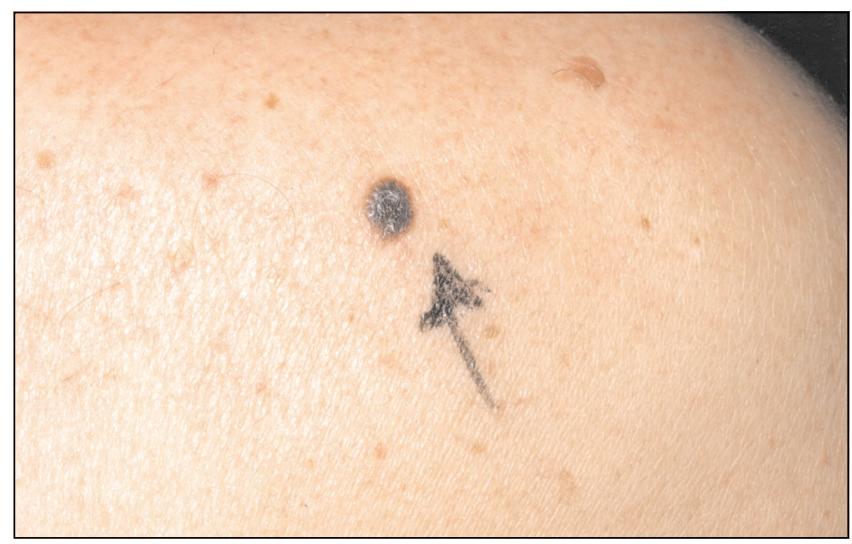

Figure 1) Photograph showing malignant melanoma on the right shoulder

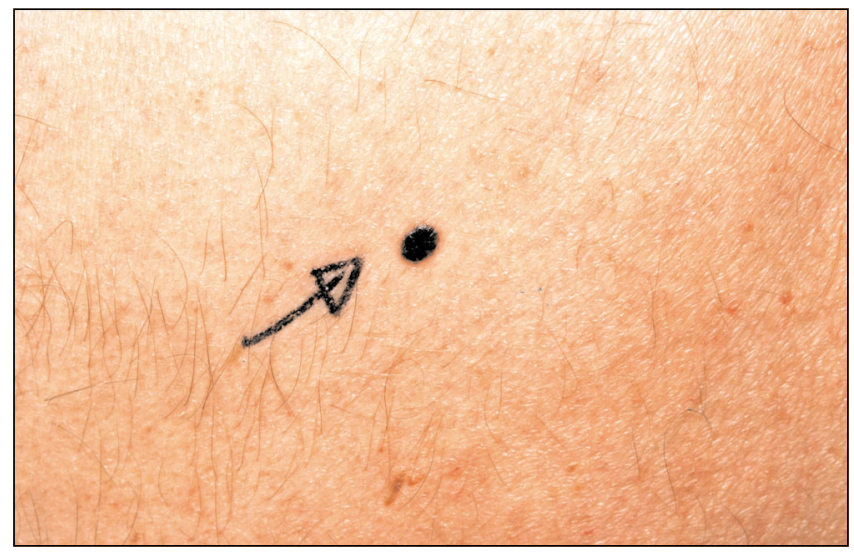

Figure 2) Photograph showing malignant melanoma on the back

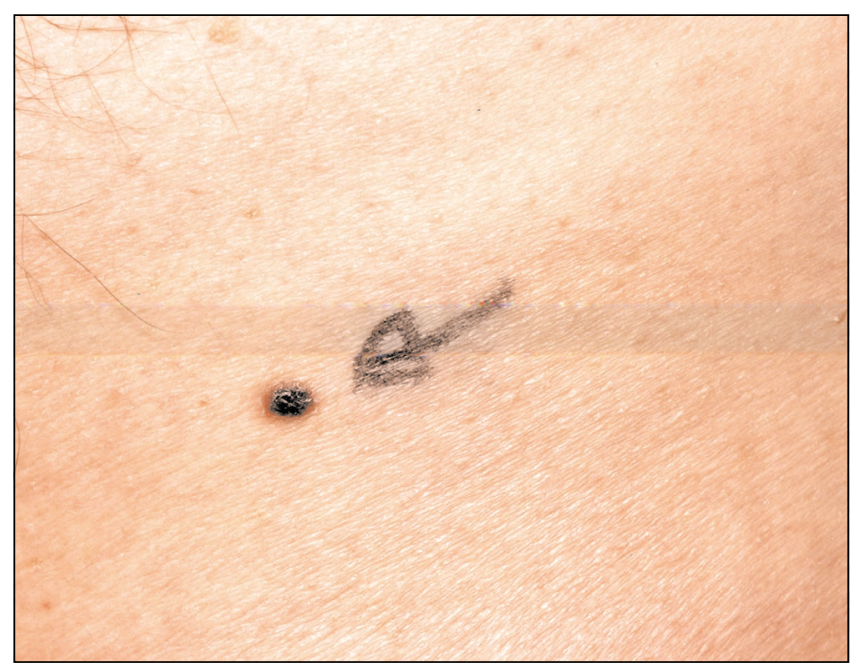

Figure 3) Photograph showing malignant melanoma on the left of the groin

$1.2 \mathrm{~mm}$ [Figure 1]), back (1.4 mm [Figure 2]), and left groin $(0.86 \mathrm{~mm}$ [Figure 3]). Histologically, the lesions from the left shoulder and the left axilla were dysplastic naevi.

\section{DISCUSSION}

Atypical mole (dysplastic naevus) is an established risk factor for the development of melanoma (1). It is, however, uncommon for multiple primary melanomas to arise from naevi

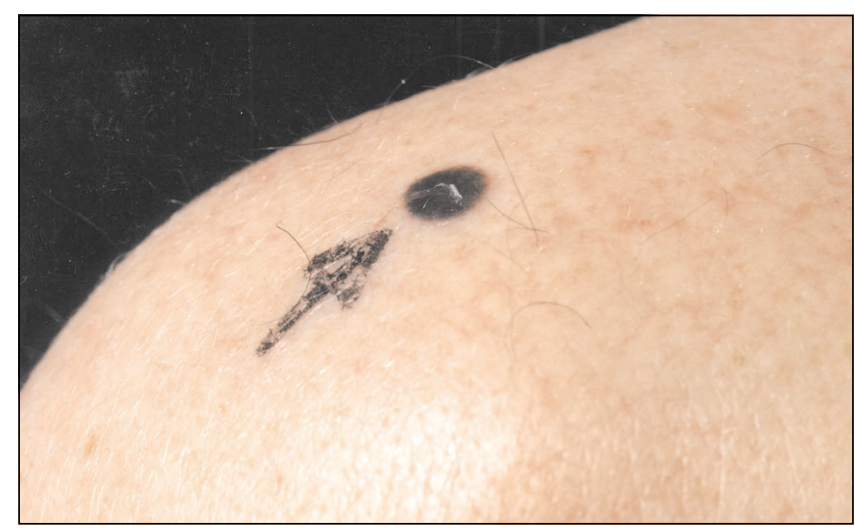

Figure 4) Photograph showing dysplastic naevus on the left shoulder

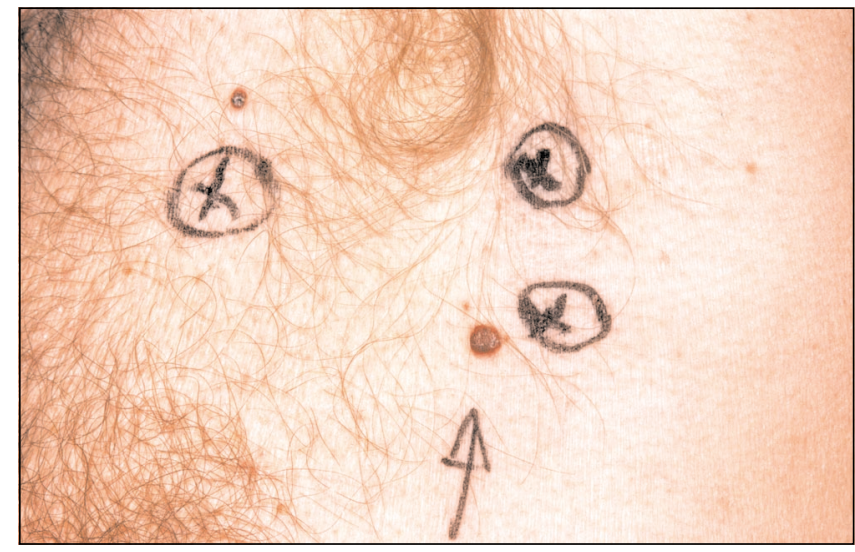

Figure 5) Photograph showing dysplastic naevus on the left axilla

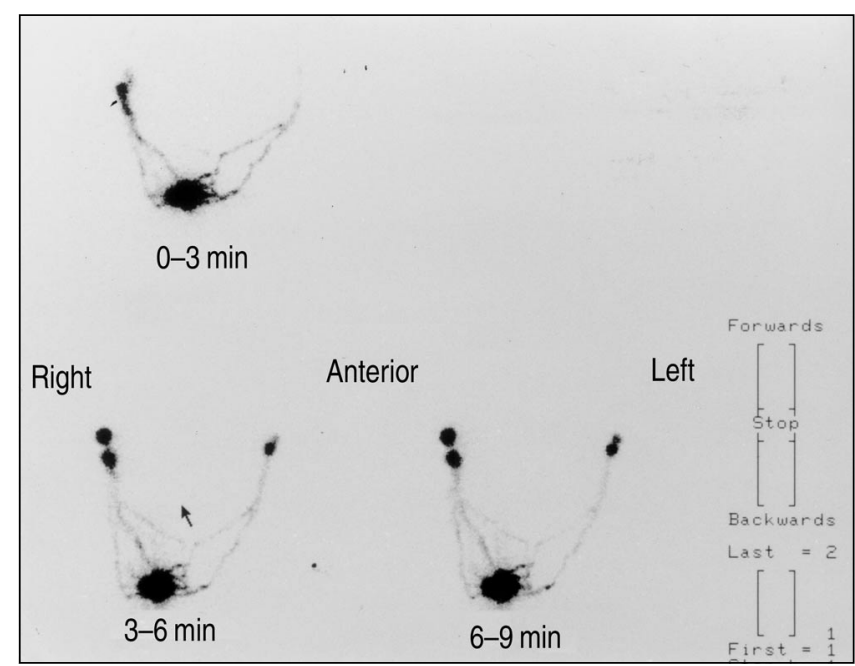

Figure 6) Dynamic image of the lymphoscintigram showing simultaneous drainage to the left and right axillae

in the same person. It is even rarer for them to arise synchronously (2).

Atypical mole syndrome is well represented in this patient by the following classic features (3): one or more malignant melanomas, one or more melanocytic naevi larger than $6 \mathrm{~mm}$ in diameter and one or more melanocytic naevi with clinically atypical (dysplastic) features.

In all patients with atypical mole syndrome, the relative 
risk of developing melanoma is $60 \%$, and a 10 -year cumulative risk is $11 \%$. Marghoob et al (4), found that the chance of developing a second melanoma over the course of 10 years was $35 \%$ in patients with atypical mole syndrome, compared with $17 \%$ in controls who had melanoma but not atypical mole syndrome. Other risk factors in this patient were fair skin and exposure to sun. This patient worked outdoors and, as such, repeated exposure to sun was inevitable. He was also intermittently exposed during annual holidays abroad with increased relative risk.

Despite extensive public education campaigns, Brandberg et al (5) have shown that sun-related behaviour in people with dysplastic naevus, essentially, is not different from that in the general population. More effort needs to be made to drive home this message: avoid excessive sun exposure.

\section{MANAGEMENT}

The management of multiple melanomas is essentially the same as that of single melanomas - they are excised with adequate margins. The use of lymphoscintigraphy and sentinel node biopsy (6) is still evolving, and while it may contribute significantly to the management of isolated melanoma, we admit that the eventual multiplicity of the presentation in this patient made the investigation difficult to interpret.

The incidence of malignant melanoma may continue to

\section{REFERENCES}

1. Kelly JW, Yeatman JM, Regalia C, et al. A high incidence of melanoma found in patients with multiple dysplastic naevi by photographic surveillance. Med J Aust 1997;167:191-3.

2. Savoia P, Quaglino P, Verrona A, Bernego MG. Multiple primary malignant melanomas: analysis of 49 cases. Melanoma Res 1998;8:361-5.

3. Marghoob AA. The dangers of atypical mole (dysplastic naevus) syndrome. Postgrad Med 1999;105:147-64.

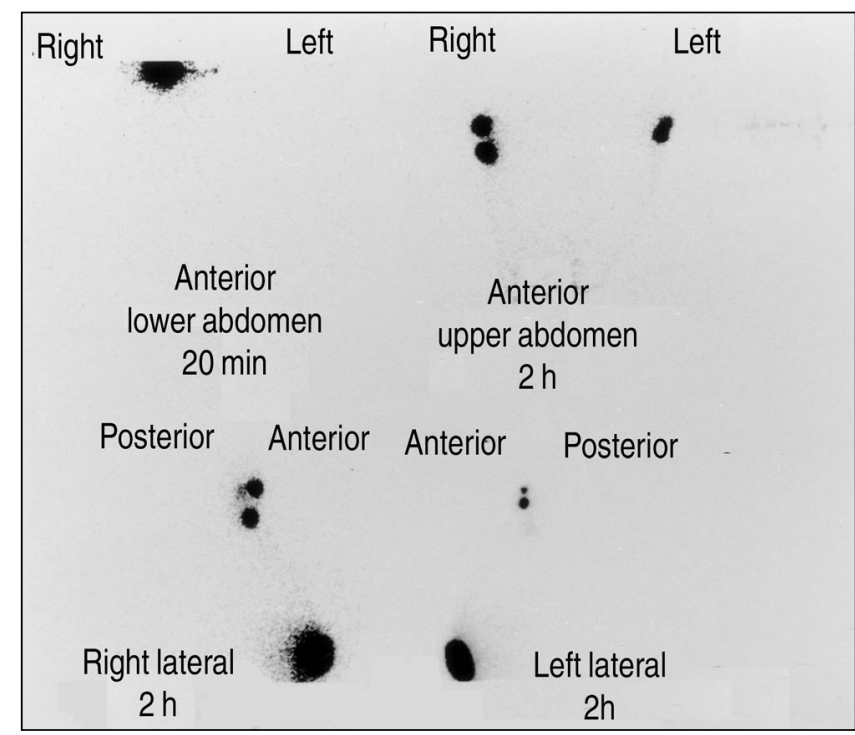

Figure 7) Lymphoscintigram image showing sentinel nodes in both axillae

rise. However, intense public education and surveillance by clinical and photographic means will at least ensure early diagnosis and treatment.

4. Marghoob AA, Slade J, Kopf AW, et al. Risk of developing multiple primary cutaneous melanomas in patients with the classic atypical mole syndrome: a case-control study. Br J Dermatol 1996;135:704-11.

5. Brandberg Y, Jonell R, Broberg M, Sjoden PD, Rosdahl I. Sun-related behaviour in individuals with dysplastic naevus syndrome. Acta Derm Venereol 1996;76:381-4.

6. Reintgen D, Balch CM, Kirkwood J, Ross M. Recent advances in the care of the patients with malignant melanoma. Ann Surg 1997;225:1-14. 